\title{
Multi-electrode System for Electrokinetic Remediation of Paddy Soil to Remove Toxic Metals
}

\author{
Guohua Chu ${ }^{l}$, Jie Xiao ${ }^{1}$, Yingjie Zhang ${ }^{1, *}$, Peng Dong ${ }^{1, *}$, G P Nayaka $^{l}$, Qi Meng ${ }^{1}$, \\ Ding Wang ${ }^{1}$, Xin Sun ${ }^{2}$, Mark Baumgartel', Jinmei Ji ${ }^{1}$ \\ ${ }^{1}$ National and Local Joint Engineering Laboratory for Lithium-ion Batteries and Materials Preparation \\ Technology, Key Laboratory of Advanced Battery Materials of Yunnan Province, Faculty of \\ Metallurgical and Energy Engineering, Kunming University of Science and Technology, Kunming \\ 650093, People's Republic of China \\ ${ }^{2}$ Faculty of Environmental Science and Engineering, Kunming University of Science and \\ Technology, Kunming 650093, People's Republic of China \\ ${ }^{3}$ Faculty of Foreign Languages and Cultures, Kunming University of Science and Technology, \\ Kunming 650093, People's Republic of China \\ *E-mail: dongpeng2001@126.com
}

doi: $10.20964 / 2018.12 .47$

Received: 7 May 2018 / Accepted: 29 June 2018 / Published: 5 November 2018

Electrokinetic remediation technology is a promising method to recover metal-contaminated soil. In the present study, the experiment was carried out in a reactor cell which was made of bricks (length $\times$ width $\times$ height $=560 \mathrm{~mm} \times 560 \mathrm{~mm} \times 300 \mathrm{~mm}$ ), containing $20 \mathrm{~kg}$ soil over 60 days. Six electrodes were vertically inserted as anodes on both the sides of soil column, while two electrodes were vertically inserted in the middle of soil area as cathodes. And a voltage gradient of $1.4 \mathrm{~V} / \mathrm{cm}$ was constantly implemented in the experimental system. The solution of $0.1 \mathrm{M}$ citric acid $+0.1 \mathrm{M}$ sodium chloride $(\mathrm{pH}=3.24)$ was added into the experiment as electrolyte. After 60-day treatment, high concentration of residual lead and cadmium were obtained in the center of soil column. Compared with $57.02 \%$ and $69.95 \%$ of lead and cadmium removal efficiencies in whole experiment, $63.93 \%$ and $76.87 \%$ of lead and cadmium removal efficiencies were obtained in soil column excluding the central zone. X-ray Fluorescence Spectrometry (XRF), X-ray Powder Diffraction (XRD) and Scanning Electron Microscopy (SEM) studies were used to detect changes of soil particle in soil samples.

Keywords: Electrokinetic remediation; Paddy soil; Lead; Cadmium

\section{$\underline{\text { FULL TEXT }}$}


(C) 2018 The Authors. Published by ESG (www.electrochemsci.org). This article is an open access article distributed under the terms and conditions of the Creative Commons Attribution license (http://creativecommons.org/licenses/by/4.0/). 